\title{
OBSERVACIONS SOBRE LA INFORMACIÓ CIENTÍFICA REFERENT A LES DROGUES EN ALGUNS LLIBRES DE TEXT D'E.S.O.
}

\author{
Francesc Martínez Vergés. Àrea de Ciències de la Naturalesa. IES Torredembarra
}

Una de les coses que comporta l'Educació Secundària Obligatòria (ESO), respecte als estudis que substitueix, és la introducció de noves matèries en els plans d'estudi (currículums) o de nous aspectes a treballar dins de matèries tradicionals. En el cas de l'àrea de Ciències de la Naturalesa de l'ESO, tal com ha estat organitzada pel decret 96/1992, de 28 d'abril, pel qual s'estableix l'ordenació dels ensenyaments de l'educació secundària obligatòria (DOG del 13/5/1992) un dels continguts a treballar és: "l'ésser humà: el cos humà i la salut». En aquest context, un dels objectius terminals que han d'assolir els alumnes és: "Valorar iconèixer els habits saludables tant individuals com colllectius en relació amb l'alimentació, l'esport, els factors que alteren l'equilibri del sistema nerviós ila necessitat de prendre mesures adequades per no consumir drogues...». Per això, en els llibres de text de l'àrea de Ciències de la Naturalesa de l'ESO trobem algun apartat, més o menys extens, dedicat a les drogues.

El tema de les drogues és un cas paradigmàtic de matèria pluridisciplinària, interdisciplinària $\mathrm{i}$ molt complexa des de tots els punts de vista. Cal considerar que, entre d'altres professionals, treballen en qüestions relacionades amb les drogues: farmacèutics, metges (especialistes en salut pública, forenses, psiquiatres, etc.), farmacòlegs, químics orgànics, bioquímics, advocats, etc. Un tema que es pot estudiar des de tants punts de vista (jurídic, químic, farmacognòstic, farmacològic, toxicològic...), òbviament, seria més difícil de copsar i resumir en unes línies de llibre de text d'ESO que, posem per cas, un tema com: Vertebrats.

Per altra banda, una idea recurrent en la Reforma dels ensenyaments secundaris és la de treballar en la línia de conèixer les idees prèvies dels alumnes i trobar estratègies d'intervenció pedagògica per fer-los canviar si són errònies. Això és molt interessant, però alhora és molt optimista en el que toca als professors perquè dóna a entendre que partim nets d'idees errònies. Malauradament, la realitat és una altra.

És possible trobar errors voluntaris, és a dir, menti- des, o involuntaris en qualsevol llibre de text (o no). Lògicament, la possibilitat d'introduir errors científics en un llibre augmenta en la proporció en què l'autor s'endinsa en un camp complex que no és el de la seva especialitat 0 competència.

Aquests comentaris els fem perquè hem observat, en diversos llibres de text de l'àrea de Ciències de la Naturalesa d'ESO, errors de diverses categories que fan referència a les drogues. Alguns d'aquests errors palesen que els autors no han copsat prou ni els conceptes fonamentals del tema ni la seva complexitat real. (Respecte a les drogues, cal utilitzar com a bibliografia bàsica els llibres de Farmacologia, els de Farmacognòsia, els de Química de Productes Naturals, els de Salut Pública i similars, més que els fulletons divulgatius d'Ajuntaments, d'alguns serveis educatius i d'altres entitats que darrerament s'interessen en aquestes qüestions).

A continuació indiquem alguns d'aquests errors amb l'ànim de col-laborar en la seva esmena i com a element de reflexió sobre la necessitat de vigilar, el més acuradament possible, tant les nostres idees prèvies com el rigor científic dels llibres de text, siguin del nivell educatiu que siguin.<smiles>CN1CC(C(=O)O)CC2c3cccc4[nH]cc(c34)CC21</smiles>

Fórmula plana de l'àcid lisèrgic. La seva dietilamida constitueix I'LSD.

\section{Anàlisi d'alguns textos escolars}

En el llibre de text de J.M. Blanch (1995) trobem, a la pàgina 67: "Des del punt de vista de la farmacologia, una droga és un principi actiu d'origen natural (la substància purgant del rici o la tranquil.litzant que conté 


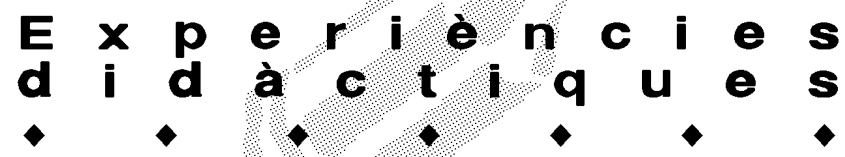

la til.la, etc.) o sintètic que, convenientment preparat, s'administra per guarir».

Davant aquesta afirmació, cal fer les següents observacions:

a) La Farmacognòsia és una de les Ciències que estudia les drogues. Farmacognòsticament, llevat dels països anglosaxons, diferenciem entre el concepte de droga (producte d'origen natural d'aplicació mèdicofarmacèutica, o bé utilitzat com a droga d'abús o d'alguna forma relacionada — verí, etc.) i el concepte de principi actiu o principis actius d'una droga. Per exemple, l'opi és un droga i la morfina és un dels principis actius de l'opi. (En l'àmbit anglosaxó, com que fan servir el terme drug tant per al nostre concepte droga com per al concepte principi actiu, s'ha de parar atenció per saber a què es refereixen cada vegada en concret). Evidentment, el llibre de Blanch confon (barreja) els conceptes de droga i de principi actiu i, literalment, arriba a dir: "una droga és un principi actiu...».

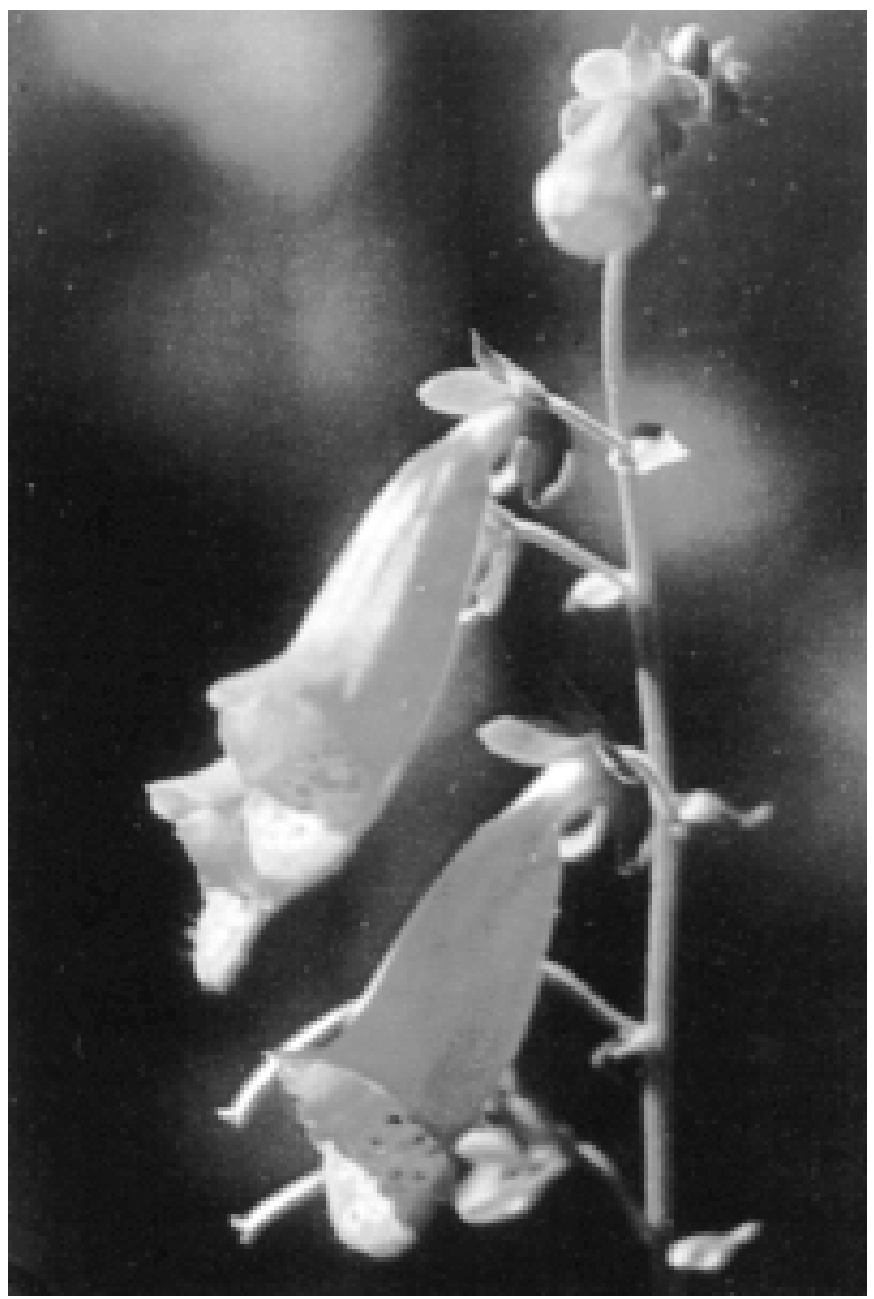

Digital purpúria. Planta rica en el principi actiu anomenat digitalina. b) La substància purgant del ricí (el principi actiu de la droga ricí) és coneguda (l'àcid ricinoleic de l'oli de ricí), si bé actualment no és gaire utilitzada en terapèutica. Ara bé, ni la til-la com a droga ni cap dels seus components tenen efecte tranquil-litzant demostrat. (Que una droga s'hagi utilitzat tradicionalment amb una suposada acció farmacològica no vol dir que la Farmacologia pugui demostrar-ne l'acció suposada!).

En el text de la fotografia de la pàgina 68 (del llibre de Blanch) trobem: "La didalera conté una droga anomenada digitalina". I en aquesta mateixa pàgina afegeix: "Hi ha cinc tipus principals de drogues: al./ucinogenes...».

En aquest cas cal indicar que:

c) Es torna a palesar la confusió de conceptes entre droga i principi actiu: s'hauria de dir: "La didalera és un droga que conté un principi actiu anomenat digitalina».

d) S'està donant com a classificació de drogues, en general, la classificació de les substàncies que actuen, principalment, sobre els centres superiors del sistema nerviós central.

En el crèdit de Ciències de la Naturalesa, El cos humà, de M. Fornells (1996), trobem, a la pàgina 56: "Una droga és una substància química, d'origen farmacològic o no, capaç de provocar en la persona afectada un desig compulsiu, és a dir, no controlat, de consumir aquella substància».

"...La dependència psíquica és comuna a totes les drogues, a algunes de les quals se suma l'efecte de la dependència física”.

A la figura 1 reproduïm l'esquema a què fa referència el text en lletra cursiva.

Val a dir que:

a) El concepte de droga, en el sentit més ampli, ja ha estat comentat abans. En tot cas, no té sentit dir que una droga és "una substància química, d'origen farmacològic o no». Potser els autors volien dir d'origen natural o sintètic. Però, a més a més, una droga (en el sentit

\begin{tabular}{|c|c|c|}
\hline $\begin{array}{l}\text { Tipus de } \\
\text { drogues }\end{array}$ & Susbtàncies & Dependència \\
\hline $\begin{array}{l}\text { Depressores del } \\
\text { sistema nerviós } \\
\text { central }\end{array}$ & $\begin{array}{l}\text { Opiacis } \\
\text { Barbitúrics } \\
\text { Alcohol }\end{array}$ & $\begin{array}{l}\text { Física i psico- } \\
\text { lògica }\end{array}$ \\
\hline Sedants & $\begin{array}{l}\text { Benzodia- } \\
\text { zepines }\end{array}$ & $\begin{array}{l}\text { Sobretot psico- } \\
\text { lògica menys de } \\
\text { tipus físic }\end{array}$ \\
\hline Estimulants & $\begin{array}{l}\text { Amfetamines } \\
\text { Cocaïna }\end{array}$ & Psicològica \\
\hline Al·lucinògenes & $\begin{array}{l}\text { LSD } \\
\text { Marihuana }\end{array}$ & Psicològica \\
\hline
\end{tabular}

Figura 1. Les drogues i les seves dependències. 


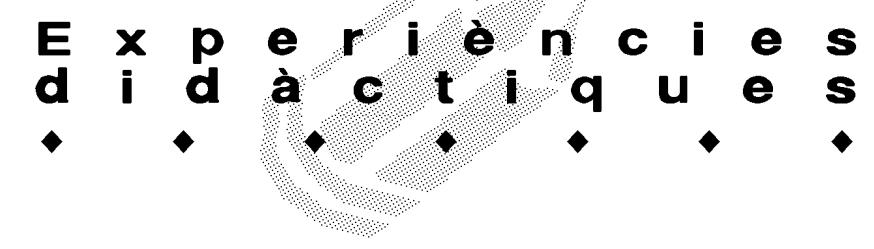

anglosaxó de la paraula) pot ser una substància químicament pura, si més no en teoria (cocaïna, morfina, etc) o pot ser un producte molt complex, com per exemple la marihuana, que conté, entre d'altres substàncies, centenars de cannabinoids, alguns dels quals són substàncies psicotròpiques. Per tant, dir que «una droga és una substància química» és molt poc escaient.

b) $\mathrm{Hi}$ ha drogues i principis actius psicotròpics com l'LSD, el peiot (i el seu principal principi actiu -la mescalina-), etc., que no creen dependència psíquica.

Al crèdit 6, L'organisme. Herència i evolució, d'A. Caamaño (1994) trobem, a la pàgina 42, la taula que reproduïm a la figura 2 .

Cal fer notar que:

a) El cannabis no crea dependència física.

b) L'LSD no crea dependència física.

c) En la taula que reproduïm a la figura 2 es dóna el

\begin{tabular}{|c|c|c|c|}
\hline Drogues & $\begin{array}{l}\text { Dependència } \\
\text { psicològica }\end{array}$ & $\begin{array}{l}\text { Dependèn- } \\
\text { cia física }\end{array}$ & $\begin{array}{l}\text { Risc de trans- } \\
\text { torns provo- } \\
\text { cats per l'ús } \\
\text { continuat }\end{array}$ \\
\hline Alcohol & *** & *** & *** \\
\hline Amfetamines & ** & * & *** \\
\hline Analgèsics & * & * & * \\
\hline Cafeïna & * & $?$ & * \\
\hline Cannabis & ** & * & * \\
\hline Cocaïna & *** & * & $\star * *$ \\
\hline Heroïna & *** & *** & *** \\
\hline $\begin{array}{l}\text { LSD (al-luci- } \\
\text { nògens) }\end{array}$ & * & $?$ & ** \\
\hline Morfina & *** & *** & $\star \star \star ~$ \\
\hline
\end{tabular}

Figura 2. Dependències i riscos provocats per l'ús de drogues.

mateix grau de perillositat a l'alcohol, les amfetamines, I'heroïna i la morfina que al tabac. De cap manera és comparable el consum de productes com l'heroïna, l'alcohol o la cocaïna amb el consum de tabac, ni pel que fa als efectes immediats de tot tipus (inclosa la toxicitat aguda) ni pel que es refereix al consum a llarg termini (inclosa la toxicitat crònica). Presentar-ho en una taula d'aquesta mena, com si fossin coses equivalents, pot contribuir més a la confusió mental que a la informació veraç i responsable. (Una altra qüestió és que el tabac perjudiqui la salut, però, repetim-ho, de cap manera és comparable el tabaquisme amb l'efecte devastador de productes com l'heroïna, la cocaïna o l'alcohol).

En el llibre de text: Área de Ciències de la Naturalesa. Biologia. Segon Cicle d'Educació Secundària Obligatòria (3). Crèdit comú: «El cos humà i la salut», trobem, en la pàgina 75, l'esquema que es reprodueix a la figura 3.

Davant aquestes afirmacions, cal fer notar que:

a) La cocaïna afecta el septe nasal quan s'administra aspirant-la pel nas, perquè entre d'altres efectes farmacològics té un potent efecte vasoconstrictor, que arriba a necrosar els teixits del septe nasal. Aquesta zona, òbviament, no queda afectada si s'administra la cocaïna per via intravenosa.

b) La toxicitat de la marihuana, aguda o crònica, és una qüestió àmpliament estudiada i debatuda, de la qual resulta molt difícil treure cap conclusió contundent. Per exemple, no s'ha pogut demostrar definitivament que el consum crònic de cannabis afecti significativament el sistema immunitari del consumidor.

Al llibre de T.M. Coreig (1995), trobem, a la pàgina 86: "Substàncies estimulants. Activen el sistema nerviós, provoquen una major activitat muscular i intel-lectual i, per tant, fan minvar la sensació de fatiga i mitiguen la son. Exemples: la cafeïna; la cocaïna; els al/lucinògens -com ara l'anomenat $\angle S D$-, que produeixen una forta distorsió de la percepció i, per tant, de la realitat; les amfetamines; les anomenades drogues sintètiques: èxtasi, etc.».

Cal puntualitzar que:

a) A la llum dels coneixements farrmacològics actuals, no és gaire correcte agrupar sota el mateix encapçalament d'estimulantsal-lucinògens com l'LSD (que no provoca cap augment de l'activitat muscular) i psicoestimulants com les amfetamines.

\begin{tabular}{|c|c|c|c|}
\hline Droga & Es pren... & Efectes immediats & Efectes a llarg termini \\
\hline Cocaïna & Aspirada & $\begin{array}{l}\text { Eufòria i sensació d'estar } \\
\text { més lúcid. Al.lucinacions. }\end{array}$ & $\begin{array}{l}\text { Transtorns mentals i destrucció dels teixits nasals, ja } \\
\text { que s'aspira pel nas. }\end{array}$ \\
\hline Heroïna & Injectada & $\begin{array}{l}\text { Estat de satisfacció, indife- } \\
\text { rència i absència de dolor. }\end{array}$ & $\begin{array}{l}\text { Transtorns mentals. Risc de contreure hepatits B o sida } \\
\text { a causa de l'ús de xeringues no estèrils. }\end{array}$ \\
\hline $\begin{array}{l}\text { Inhalants (dis- } \\
\text { solvents i gomes } \\
\text { d'enganxar) }\end{array}$ & Aspirats & $\begin{array}{l}\text { Sensació de lleugeresa } \\
\text { mental, desorientació i son }\end{array}$ & $\begin{array}{l}\text { Al.lucinacions i deliris. Lesions cerebrals i alteracions en } \\
\text { les cèl-Iules sanguínies. Risc d'accidents per asfíxia, ja } \\
\text { que s'inhalen amb bosses de plàstic. }\end{array}$ \\
\hline Marihuana & Fumada & Al-lucinacions. & Bronquitis crònica, malalties infeccioses i càncer de pulmó. \\
\hline
\end{tabular}

Figura 3. Esquema sobre algunes de les drogues i els seus efectes. 


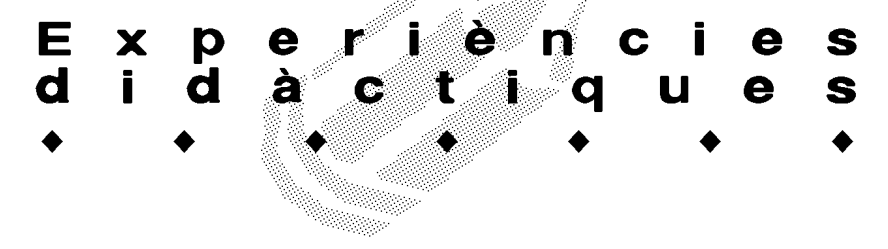

b) Totes les amfetamines són sintètiques. Per tant, la distinció entre amfetamines i drogues sintètiques no té sentit.

Al tex de L. del Carmen (1995) es diu:

a) En l'apartat Cannabis de la pàgina 162: "És una planta de la qual s'extreuen diversos derivats, com la marihuana ("herba") o l'haixix ("xocolata")». En aquesta mateixa pàgina trobem el dibuix que reproduïm en la figura 4.

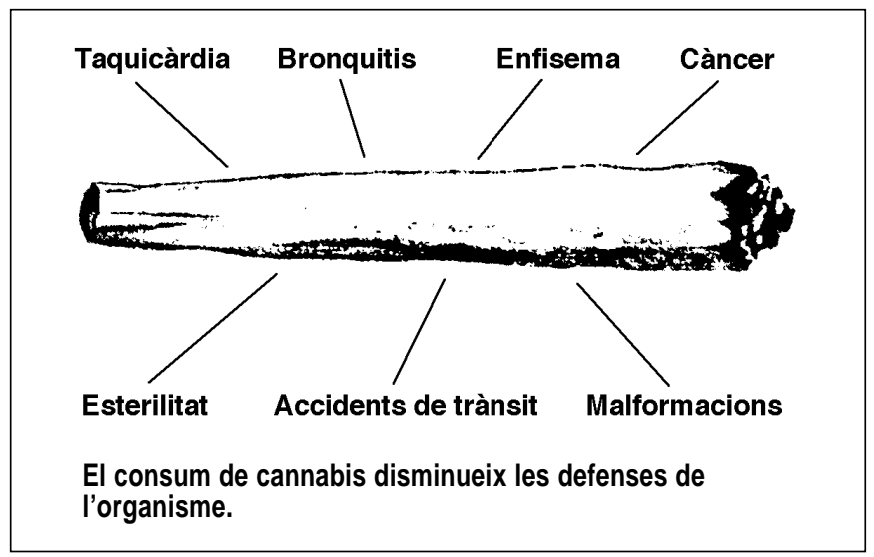

Figura 4. II-lustració sobre el consum de cannabis.

b) En l'apartat Cocaïna, de la pàgina 163, trobem: "La cocaïna provoca una gran dependència psíquica i l'alteració del caràcter, que es torna cada cop més irritable i agressiu. També ocasiona lesions al septe nasal».

Observacions a fer:

a) Com que la marihuana no és un producte extractiu, no és correcte dir que s' "extreu"de la planta "cannabis". Els farmacognostes utilitzen expressions del tipus: "la marihuana és una droga que s'obté del "Cannabis sativa».

b) Sobre la distinció entre marihuana i haixix cal recordar que, per a alguns autors, marihuana i haixix són noms diferents de la mateixa droga. Per a altres, la marihuana són les summitats floríferes o fructíferes de "Cannabis sativa", de les quals no s'ha extret la resina, mentre que el haixix és la resina d'aquesta planta.

c) Sobre els efectes del consum crònic de cannabis ja hem fet abans un comentari. Conduir sota els efectes d'aquesta droga pot ser fatal, però està per demostrar que pugui provocar esterilitat masculina, malformacions o alguna mena d'immunodeficiència.

c) L'efecte de la cocaïna sobre el septe nasal ja s'ha comentat anteriorment.

\section{Conclusions}

En funció del que s'ha exposat fins ara, s'observen errors científics considerables sobre el tema de les drogues en diversos llibres de text d'ESO. Caldria tenir en compte que l'elaboració de textos escolars, del nivell que siguin, és una feina de gran responsabilitat, ja que

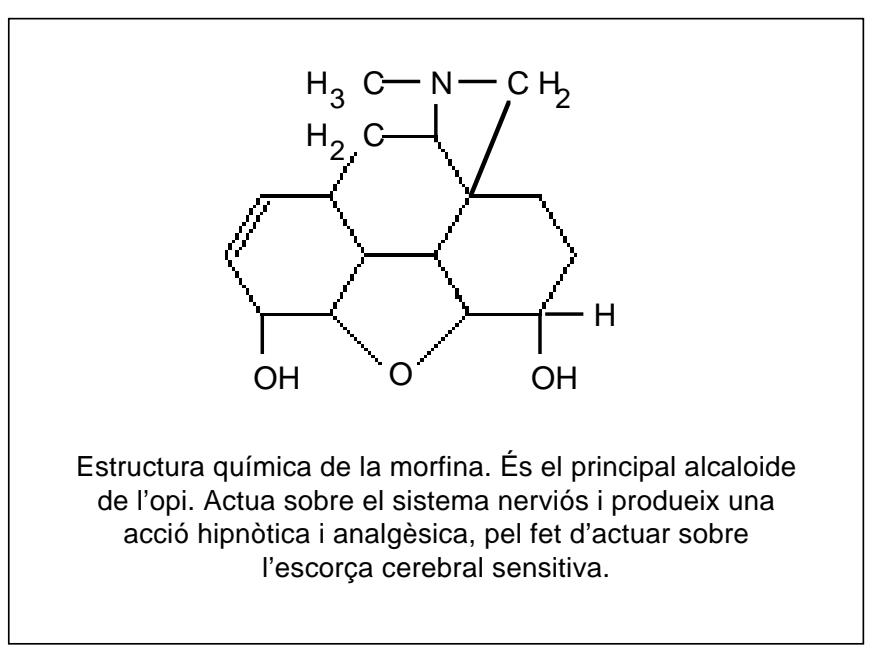

I'usuari confia a trobar-hi una informació consolidada. Convidem els autors que extremin les precaucions i contrastin al màxim les seves fonts d'informació.

\section{Referències bibliogràfiques}

Àrea de Ciències de la Naturalesa. Biologia. Segon Cicle d'Educació Secundària Obligatòria (3). Crèdit comú: "El cos humà i la salut" Editorial EDEBÉ. Barcelona. 1995.

BLANCH, J.M., i altres. Crèdit comú 5 de Ciències de la Naturalesa, $2 n$ Cicle d'ESO. Editorial Barcanova. Barcelona. 1995.

CAAMAÑO, A., i altres. L'organisme. Herència i evolució (Crèdit 6, del Projecte de Ciències Experimentals 12-16). Editorial ECIR. Paterna. 1994.

COREIG, T.M., i altres. 3. Ciències de la Naturalesa. EI cos humà: Forma ifuncions. Educació Secundària Obligatòria. Segon Cicle. Editorial Teide. Barcelona. 1995.

DEL CARMEN, L. i PEDRINACI, E. Ciències Experimentals. 3. Biologia i Geologia. Educació Secundària Obligatòria. Editorial Cruïlla. Barcelona. 1995.

FORNELLS, M., i altres. El cos humà (Crèdit de Ciències de la Naturalesa). Editorial McGraw-Hill. Barcelona. 1996. 